\title{
Climate Suitability and Vulnerability of Winter Wheat Planting in Gansu under the Background of Global Warming
}

\author{
Xing Wang1, Yuhe $\mathrm{Ji}^{2}$, Guangsheng Zhou ${ }^{2}$, Sheng Wang3 ${ }^{3}$ Xiaoying Yao ${ }^{4}$ \\ ${ }^{1}$ Northwest Regional Climate Center, Lanzhou, China \\ ${ }^{2}$ State Key Laboratory of Severe Weather (LASW), Chinese Academy of Meteorological Sciences, Beijing, China \\ ${ }^{3}$ Lanzhou Institute of Aridology, China Meteorological Administration, Lanzhou, China \\ ${ }^{4}$ Tianshui Meteorological Bureau, Tianshui, China \\ Email: wangx32@sina.com
}

How to cite this paper: Wang, X., Ji, Y. H., Zhou, G. S., Wang, S., \& Yao, X. Y. (2019). Climate Suitability and Vulnerability of Winter Wheat Planting in Gansu under the Background of Global Warming. Journal of Geoscience and Environment Protection, 7, 239-250.

https://doi.org/10.4236/gep.2019.74016

Received: September 20, 2018

Accepted: April 26, 2019

Published: April 29, 2019

Copyright $\odot 2019$ by author(s) and Scientific Research Publishing Inc. This work is licensed under the Creative Commons Attribution International License (CC BY 4.0).

http://creativecommons.org/licenses/by/4.0/

\begin{abstract}
Winter wheat is the main food crop in China. Gansu Province is a traditional winter wheat growing area, and its planting range is limited by the thermal conditions of winter. The average temperature in Gansu Province increased by $0.28^{\circ} \mathrm{C}$ per decade, higher than the China's and global average, and the warming in winter was more obvious. Therefore, it is necessary to study the climate suitability and vulnerability of winter wheat planting in Gansu. In this paper, the maximum entropy model Maxent and Arcgis software are used to select six major climatic factors including annual total radiation, annual precipitation, the warmest monthly average temperature, the coldest monthly average temperature, annual average temperature, and annual extreme minimum temperature, which construct winter wheat planting distribution-climate relationship model that studies the climate suitability and vulnerability of winter wheat during the period 1961-2015. Studies have shown that the average cold weather and annual extreme minimum temperature are the most important climatic factors affecting winter wheat in Gansu, which can reflect the low temperature conditions that winter wheat can tolerate. However, the main winter wheat planting areas in Gansu Province are distributed in arid and semi-arid rain-fed agriculture areas. Precipitation and total annual radiation are also very important constraints. At the same time, climate change has little effect on winter wheat in Gansu Province, and the area of suitable area fluctuates slightly. It shows moderate adaptation in each evaluation period.
\end{abstract}

\section{Keywords}

Winter Wheat, Climate Suitability and Vulnerability, Maxent Model, Threshold Curve 


\section{Introduction}

Crop cultivation, as a production activity that relies heavily on climatic conditions, shows more pronounced vulnerability in the context of global warming (Burton et al., 2002; Ragab \& Prudhomme, 2002; Alam et al., 2013). The changes in meteorological factors seriously affect the changes in the pattern of agricultural production resources. The changes in environmental conditions of radiation, temperature and water caused by climate change directly affect the growth of crops and the changes in phenological period, which in turn cause fluctuations in crop yields (Fernanda \& Maria, 2009; Ning, 2016). Gansu Province is located at the intersection of the three plateaus of the Qinghai-Tibet Plateau, the Loess Plateau and the Mongolian Plateau. It is also the province of China with three climatic zones including the westerly climate zone, the eastern monsoon zone and the Qinghai-Tibet Plateau climatic region. It is affected by the East Asian monsoon and the South Asian monsoon. The transition zone to the westerly climate impact system (Deng et al., 2008) is a typical climate change sensitive area and ecologically vulnerable area (Zhang et al., 2016; Han et al., 2016). The average temperature in Gansu Province increased by $0.28^{\circ} \mathrm{C}$ per decade, higher than the China's and global average, and the warming rate in winter was even higher (Shang et al., 2018; Deng et al., 2008), indicating that winter warming is more obvious. Winter wheat is the main traditional food crop in China, and the winter wheat planting range is mainly limited by the wintering heat conditions. Therefore, the winter wheat planting range is more affected by the climate.

Vegetation is a fragile surface cover type that is the result of long-term interactions between climate factors, geomorphology, soil and human activities. The area, type, structure and composition of vegetation and its spatial and event succession are determined by the climate of the geological era and the modern climate. At regional and global scales, climate is considered to be the most important factor controlling the geographical distribution of vegetation (Zhou \& Wang, 2003). Modeling and prediction of crop species distribution are very applicable in the study of ecology and crop species distribution, and important tools for studying the spatial distribution of species under environmental and climate change. There is a close relationship between species distribution and climatic and geographical environmental factors. At present, there are prediction models for potential distribution areas of various species, and they are widely used, and representative models are generalized linear models (GLM), generalized additive models (GAM), and classified regression trees (Lei \& Xu, 2010). The niche models using a wider range of predicted species distributions include Bioclim, Climex, Domain, Garp and MaxEnt (Elith et al., 2006; Wang et al., 2007) applied ROC curve analysis to predict the results of these five models. For the comparative analysis, the maximum entropy model (MaxEnt) has the largest AUC value, indicating that the prediction effect is the best. Sun \& Liu (2010) believe that using MaxEnt model to predict the distribution area of species, the results are better than other prediction models of the same kind, especially in the 
case of incomplete data distribution of species, the results can still be obtained with MaxEnt model prediction. Ma et al. (2013) used the MaxEnt model and ArcGis software to predict the potential distribution of Brassica and Woody plants in China at the "genus" level. As early as 1957, Jaynes proposed the theory of Maximum entropy (MaxEnt) for probability density assessment (Philips et al., 2004, Philips et al., 2006). Since then, MaxEnt has gradually applied in computer science and statistics, especially in Natural language processing is widely used. This theory can be expressed in bioecology as a species that, when unconstrained, will spread as much as possible, close to a uniform distribution, and can be used to predict the potential geographic distribution of a species (Phillips et al., 2006). MaxEnt model can still get satisfactory results when the species distribution data is incomplete.

Gansu winter wheat is mainly distributed in the Longdong Loess Plateau in Hedong, Gansu, the upper reaches of the Weihe River in the Loess Plateau in the west of Gansu, and the southern part of Gansu Province. It is one of the main food crops in Gansu Province. The planting area accounts for more than $20 \%$ of the total grain area of Gansu, and its planting range is affected by wintering. The limitation of thermal conditions makes it more necessary to study the climate suitability and vulnerability of winter wheat planting in Gansu in the context of climate warming.

\section{Model Applicability Evaluation}

Applying the MaxEnt model to study the climate suitability of winter wheat planting distribution in Gansu, we must first test the applicability of the MaxEnt model. Here, the model input data includes two categories: one is the geographical distribution data of the target, using the geographical distribution data of 40 winter wheat agrometeorological observation stations (showing in Figure 1) in the winter wheat growing area of Gansu; the second is the environmental variable, according to the period from 1961 to 1990 . Grid daily climate data $(10 \mathrm{~km}$ resolution), calculated by Arcgis software to 6 climatic factors, including annual total radiation, annual precipitation, warmest monthly average temperature, coldest monthly average temperature, annual average temperature, annual extreme minimum temperature the 30-year average during the base period (1961-1990) was used as an environmental input variable for constructing a distribution-climate relationship model for winter wheat planting. Import the two types of data into the MaxEnt model and set the relevant parameters to run.

First, $75 \%$ of the total data set is randomly obtained as a training subset to train the model to obtain the relevant parameters of the model; then, all the data that does not participate in the model training, i.e. the remaining $25 \%$, is used as a test subset for verification model. The ROC curve of the winter wheat planting distribution-climate relationship model based on six climatic factors is shown in Figure 2.

Using the MaxEnt model combined with six climatic factors to construct the Gansu winter wheat planting distribution-climate relationship model, the test 
subset AUC value reached 0.902 , the training subset AUC value also reached 0.931, and the AUC value was higher than 0.90 (Figure 2). It indicates that the prediction accuracy of the constructed model reaches the "very good" standard, and the MaxEnt model can be used to study the potential planting distribution of winter wheat in Gansu Province.

\section{Analysis of Influence Factors of Winter Wheat Planting Distribution}

Among the percent contribution rate and the importance of displacement, the

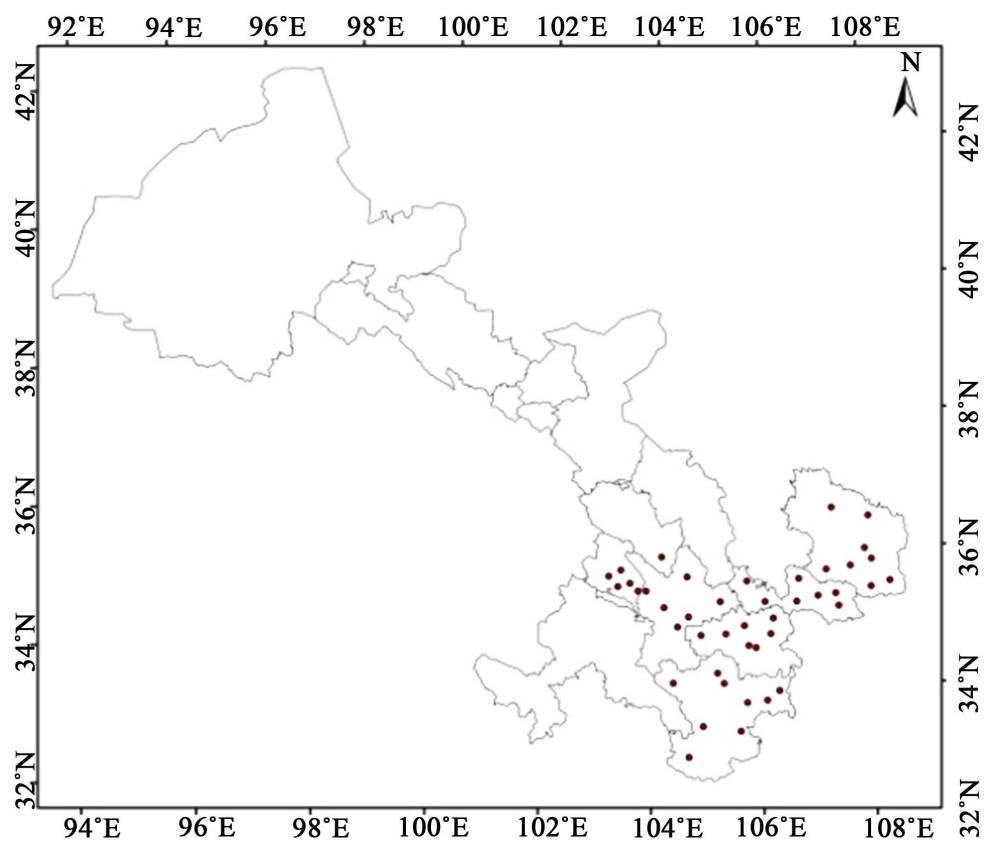

Figure 1. Geographical distribution of agro-meteorological observation station (the red points in the figure) in Gansu winter wheat growing area (Source of data: Northwest regional climate center of China).

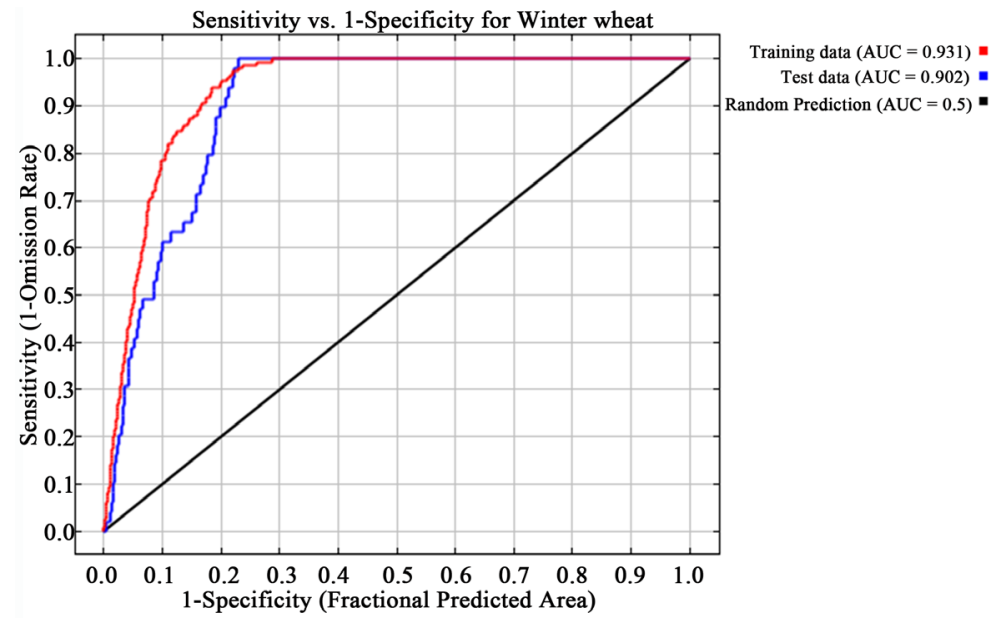

Figure 2. ROC curve of MaxEnt model simulation results for winter wheat planting distribution in Gansu. 
rankings of the effects of climatic factors on the geographical distribution of winter wheat planting are (Table 1 and Figure 3): the coldest month average temperature $(\mathrm{Tc})>$ annual precipitation $(\mathrm{P})>$ annual total radiation $(\mathrm{Q})>$ Annual Extreme Minimum Temperature $(\mathrm{Tmin})>$ The warmest monthly average temperature $(\mathrm{Tw})>$ Altitude (Ele) $>$ Annual average temperature $(\mathrm{T})$. The importance of the climatic factors on the distribution of winter wheat planting areas in Gansu Province according to the knife method shows that the coldest month average temperature and the annual extreme minimum temperature have the most important climatic factors affecting the distribution of winter wheat planting areas. At the same time, combined with the comprehensive analysis of Table 1, the importance of climate factors affecting winter wheat in Gansu Province is: the coldest month average temperature $>$ annual extreme minimum temperature $>$ annual precipitation $>$ annual total radiation. The distribution of winter wheat planting areas is usually determined by the thermal conditions of winter wheat that can be safely wintered. The coldest month average temperature and annual extreme minimum temperature can reflect the low temperature conditions that winter wheat can tolerate, but the main winter wheat planting areas in Gansu are distributed in drought and semi-arid rain-fed agricultural areas, annual precipitation and annual total radiation are also very important constraints, which is also an important difference between Gansu Province and other regions. See Figure 3.

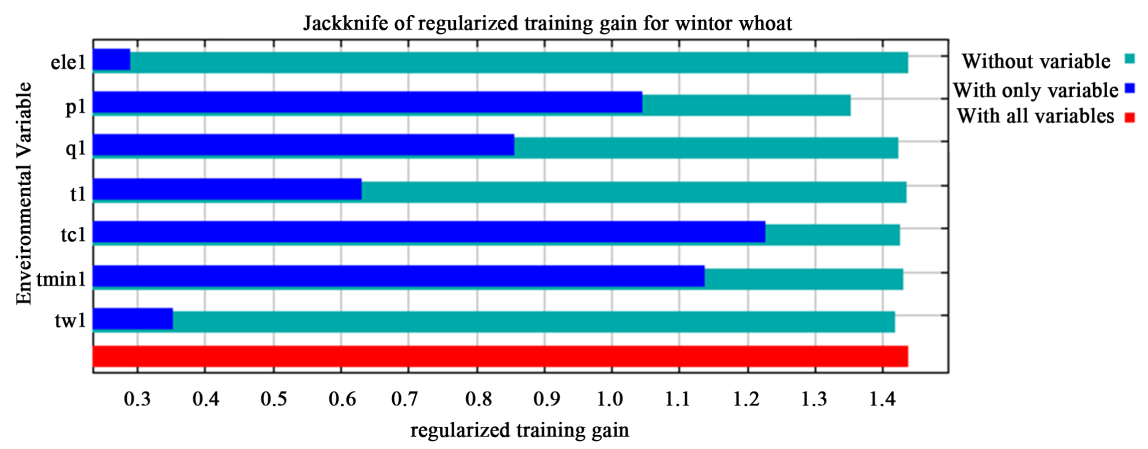

Figure 3. The score of the climatic factor in the knife method.

Table 1. Percentage contribution rate and replacement importance of environmental variables to winter wheat planting area distribution.

\begin{tabular}{ccc}
\hline Climatic factor & $\begin{array}{c}\text { Percentage of } \\
\text { contribution (\%) }\end{array}$ & $\begin{array}{c}\text { Displacement } \\
\text { importance (\%) }\end{array}$ \\
\hline The coldest month average temperature $\left(\mathrm{T}_{\mathrm{c}}\right)$ & 44.5 & 3.7 \\
Annual precipitation $(\mathrm{P})$ & 37.5 & 42.9 \\
Annual total radiation $(\mathrm{Q})$ & 8.5 & 34.8 \\
Extreme minimum temperature $\left(\mathrm{T}_{\min }\right)$ & 7.3 & 4.8 \\
Warmest monthly average temperature $\left(\mathrm{T}_{\mathrm{w}}\right)$ & 1.7 & 10.5 \\
Altitude $\left(\mathrm{T}_{\mathrm{c}}\right)$ & 0.4 & 2.5 \\
Average annual temperature $(\mathrm{T})$ & 0.3 & 0.8
\end{tabular}




\section{Classification of Climate Suitability for Winter Wheat Planting}

Based on the existence probability and climate resource guarantee rate of six climatic factors affecting the distribution of winter wheat planting in China, the climate suitability grades were classified by $60 \%, 76 \%$ and $85 \%$ climatic resource guarantee rates of six climatic factors, and the winter wheat of Gansu was constructed by MaxEnt model. The planting distribution-climate relationship model can obtain the existence probability $\mathrm{P}$ of the winter wheat crop in Gansu Province in the area to be predicted. The classification criteria are: when $0 \leq \mathrm{P}<0.05$ $\left(0.60^{6}\right)$, it is not suitable for climate; when $0.05 \leq \mathrm{P}<0.19\left(0.76^{6}\right)$, it is mildly suitable for climate; when $0.19 \leq \mathrm{P}<0.38\left(0.85^{6}\right)$, it is climate moderately suitable; when $P \geq 0.38$, it is completely suitable for climate (Zhou et al. 2015). Figure 4 shows the climatic suitability classification of winter wheat planting distribution in Gansu by the ArcGIS software during baseline period (1961-1990). Different colors represent the climatic suitability of different wheat plantings.

The climate suitable for distribution of winter wheat in Gansu Province accounts for $23 \%$ of Gansu's total area, the moderately moderate climate area accounts for $15 \%$, the mild climate suitable area accounts for $5 \%$, and the climate unsuitable area accounts for $57 \%$. Affected by climatic conditions, winter wheat planting in Gansu from 1961 to 1990 was mainly concentrated in the parts of the eastern part of Gansu Province and the southern part of Gannan. The climate unsuitable area is in the Hexi area and the Gannan Plateau.

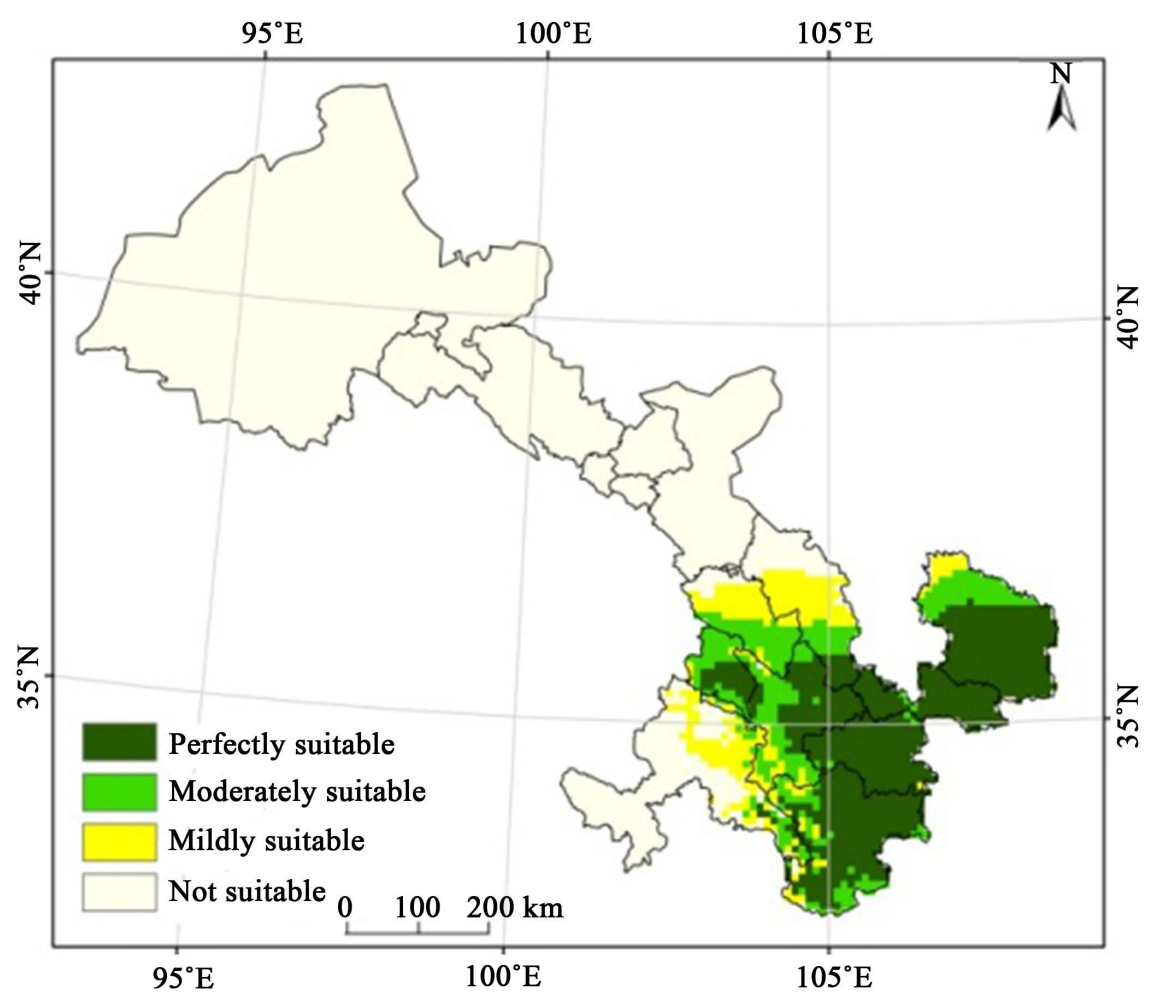

Figure 4. Climate suitability of winter wheat planting distribution in Gansu. 


\section{Threshold Analysis of Winter Wheat Impact}

Using existence probability corresponding curve of climatic factors affecting the distribution of winter wheat (Figure 5), the curves are irregularly distributed in the shape of a bell. This bell-shape distribution means that the basic performance is that the existence probability of winter wheat increases with the increase of climatic factors and then decrease. The distribution of climate suitability of winter wheat in Gansu can be given in Figure 5 and Table 2. The completely suitable areas are distributed in Tianshui, Pingliang, Longnan City, southern Qingyang, Dingxi East, south of Baiyin City, Central Linxia, Gannan Prefecture; moderately suitable areas are distributed in the north-central part of Qingyang, southern Lanzhou, southwest of Dingxi, The central and southern parts of Baiyin City, the southern and northern parts of Linxia Prefecture, the western part of Gannan Prefecture, and the southern part of Gannan Prefecture; the mildly suitable areas are distributed in the northern part of Qingyang City, the central part of Baiyin City, the northern part of Lanzhou City, the eastern part of Gannan Prefecture, the part of Dingxi City, and the part of Longnan City and Wuwei City, China.

\section{Distribution Pattern and Dynamic Change of Climatically Suitable Regions of Winter Wheat}

MaxEnt simulated the dynamic changes of suitable areas of winter wheat in Gansu Province in the period of 1961-1990, 1966-1995, 1971-2000, 1976-2005, 1981-2010 and 1986-2015 (showing in Figure 6 and Figure 7 and Table 3). From the perspective of spatial distribution pattern, compared with the reference period (1961-1990), the area of fully suitable, moderately suitable, and mildly suitable areas for winter wheat planting in Gansu Province decreased slightly from 1966 to $1995(5 \%-20 \%)$. The variability of the area change in each regional classification from 1971 to 2015 was very small, and the three periods of 1966-1995, 1971-2000 and 1976-2005 were basically unchanged. Compared with

Table 2. Distribution of winter wheat planting in Gansu and climate factor thresholds in different climate-appropriate areas.

\begin{tabular}{cccc}
\hline Project & Fully suitable area & Moderately suitable area & Mildly suitable area \\
\hline $\begin{array}{c}\text { Criteria for the classification } \\
\text { Annual precipitation }\end{array}$ & $\mathrm{p} \geq 0.38$ & $0.19 \leq \mathrm{p}<0.38$ & $0.05 \leq \mathrm{p}<0.19$ \\
Warmest monthly & $416.31-762.44$ & $369.6-775.64$ & $267.96-770.97$ \\
average temperature & $16.79-23.69$ & $15.18-23.69$ & $12.88-21.63$ \\
$\begin{array}{c}\text { Annual total } \\
\text { radiation }\left(10^{4} \mathrm{~W} / \mathrm{m}^{2}\right)\end{array}$ & $11.99-13.33$ & $12.11-13.50$ & $12.99-13.77$ \\
$\quad \begin{array}{l}\text { Extreme } \\
\text { minimum temperature }\end{array}$ & $-24.98--8.64$ & $-26.36--8.95$ & $-27.6--16.19$ \\
$\begin{array}{c}\text { The coldest month } \\
\text { average temperature }\end{array}$ & $-7.81-3.04$ & $-9.04-3.03$ & $-10.57--2.96$ \\
$\begin{array}{c}\text { Average annual temperature } \\
\text { (1) }\end{array}$ & $5.68-13.96$ & $4.48-13.93$ & $2.60-8.58$ \\
\hline
\end{tabular}



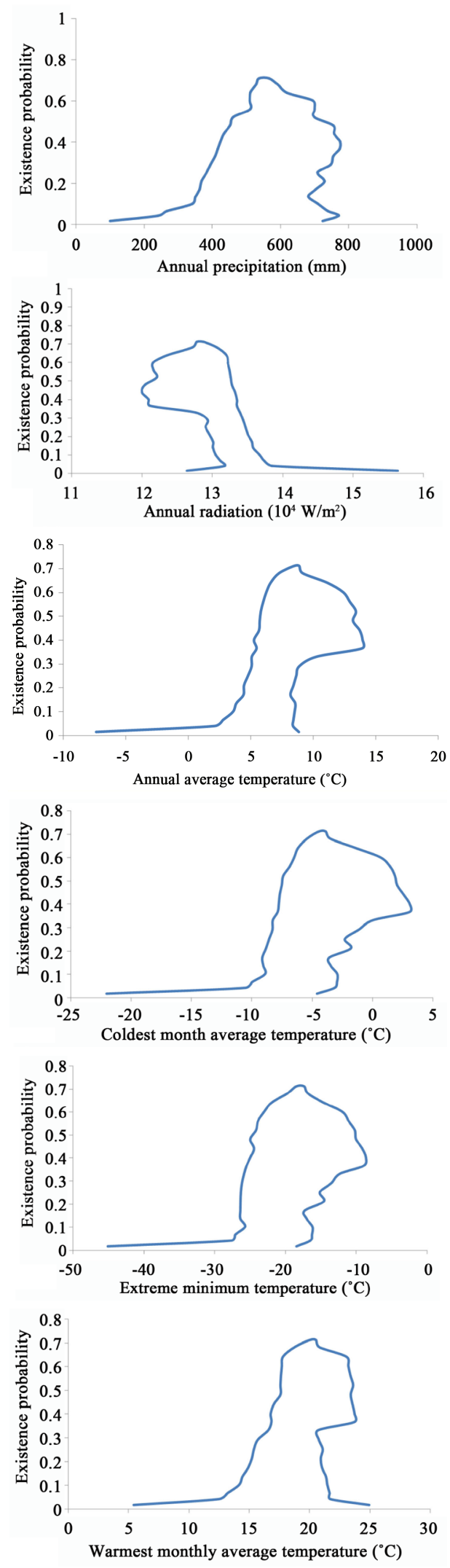

Figure 5. Relationship between existence probability and climatic factors of winter wheat in Gansu. 

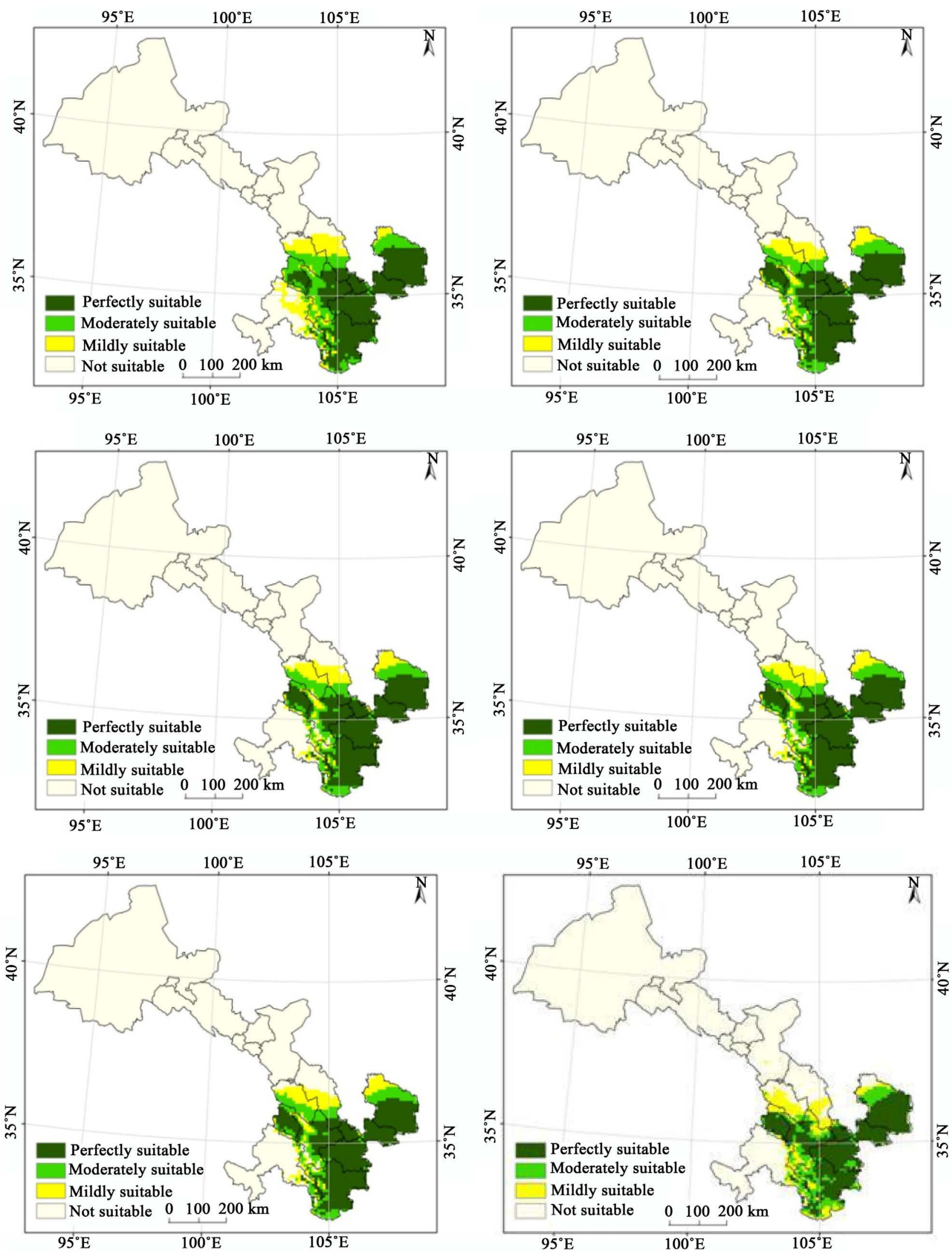

Figure 6. Dynamic change of climate suitable area for winter wheat planting distribution in Gansu. (a) 1961-1990; (b) 1966-1995; (c) 1971-2000; (d) 1976-2005; (e) 1981-2010; (f) 1986-2015. 


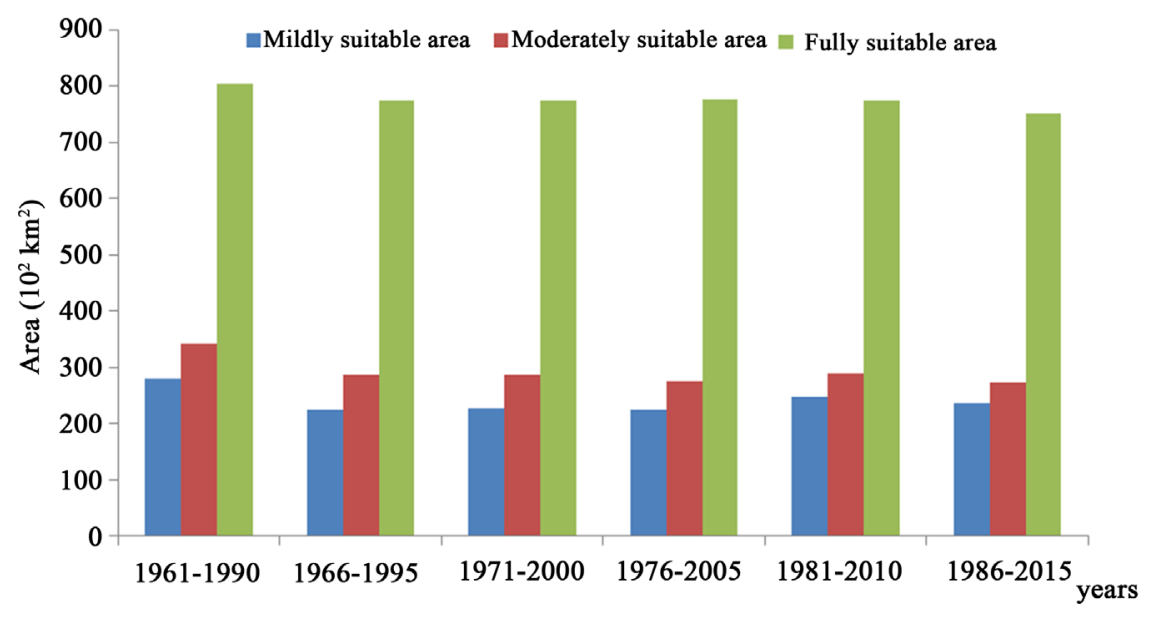

Figure 7. Dynamic change of climate suitable area change of winter wheat in Gansu.

Table 3. Changes in the area of different climate suitable areas of winter wheat in Gansu Province $\left(10^{2} \mathrm{~km}^{2}\right)$.

\begin{tabular}{cccccccc}
\hline Regional classification & 1961-1990 & 1966-1995 & 1971-2000 & 1976-2005 & 1981-2010 & 1986-2015 \\
\hline Mildly suitable area & 281 & 224 & 227 & 225 & 247 & 236 \\
Moderately suitable area & 343 & 286 & 286 & 276 & 289 & 273 \\
Fully suitable area & 803 & 773 & 775 & 777 & 774 & 750 \\
\hline
\end{tabular}

the first three periods, the moderately suitable and mildly suitable areas increased slightly $(5 \%-10 \%)$ from 1981 to 2010 , and the area of fully suitable areas decreased slightly (4\%) from 1986 to 2015 , while mildly suitable. The district increased slightly (5\%).

\section{Vulnerability and Adaptability of Winter Wheat to Climate Change}

This study used the vulnerability index $(\mathrm{V})$, the adaptive index $\left(\mathrm{A}_{1}\right)$ and the extended fitness index $\left(\mathrm{A}_{e}\right)$ to assess the adaptability and vulnerability of winter wheat to climate change in Gansu. Based on the spatial analysis function of ArcGIS software, based on the reference period (1961-1990), the vulnerable areas of winter wheat planting areas, local adaptive areas and extended adaptation areas and their respective average existence probability were identified (Table 4). The vulnerability and fitness indicators are then calculated (Table 5).

Assessing the adaptability and vulnerability of winter wheat growing areas under climate impacts based on the area of the local adaptive period of the assessment period and the area ratio of the appropriate period of the base period (SR), local adaptive ( $\mathrm{Al}$ ) and vulnerability $(\mathrm{V})$, the assessment results show that, on the whole, climate change has little effect on winter wheat in Gansu Province, and the area of suitable area fluctuates slightly. It shows moderate adaptation in each evaluation period (1966-2015). 
Table 4. Area $\left(\mathrm{km}^{2}\right)$ of suitable area of winter wheat in Gansu Province in different periods and its existence probability

\begin{tabular}{|c|c|c|c|c|c|c|c|}
\hline \multicolumn{2}{|c|}{ Research period } & \multicolumn{6}{|c|}{ Evaluation data } \\
\hline \multirow{2}{*}{ Base period } & \multirow{2}{*}{ 1961-1990 } & \multirow{2}{*}{\multicolumn{3}{|c|}{$\begin{array}{c}\text { Sik }+ \text { Sim } \\
107,400\end{array}$}} & \multirow{2}{*}{\multicolumn{3}{|c|}{$\begin{array}{c}\text { Sik } \cdot \text { pik }+ \text { Sim } \cdot \text { pim } \\
36,721.2\end{array}$}} \\
\hline & & & & & & & \\
\hline \multirow{6}{*}{$\begin{array}{l}\text { Evaluation } \\
\text { period }\end{array}$} & Evaluation period & Sjk & $\mathrm{Sjk} \cdot \mathrm{pjk}$ & Sjm & $\mathrm{Sjm} \cdot \operatorname{pjm}$ & Sjl & $\mathrm{Sjl} \cdot \mathrm{pjl}$ \\
\hline & 1966-1995 & 11,000 & 440 & 128,200 & 51543 & 100 & 12 \\
\hline & $1971-2000$ & 10,100 & 393.9 & 129,100 & $51,716.6$ & 100 & 7.48 \\
\hline & $1976-2005$ & 11,400 & 424.8 & 127,900 & $51,433.6$ & 400 & 29.9 \\
\hline & $1981-2010$ & 13,200 & 467.4 & 126,200 & $50,771.2$ & 1700 & 118.6 \\
\hline & $1986-2015$ & 14,300 & 508.3 & 125,800 & $48,957.9$ & 2230 & 208.8 \\
\hline
\end{tabular}

Note: Sik + Sim is the appropriate area of the base period, Sikpik + Simpim is the sum of the product area of the reference period and the existence probability, Sjk is the vulnerable area of the assessment period, pjk is the average existence probability of the vulnerable area, and Sjm is the locality of the assessment period. The adaptive area, pjm is the existence probability of the local adaptive region average, ( $\mathrm{Sjl}$ ) is the area for expanding the adaptation period during the evaluation period, and pjl is the existence probability of expanding the average of the adaptation region.

Table 5. Evaluation of adaptability and vulnerability of winter wheat to climate change in gansu province from 1961 to 2015.

\begin{tabular}{ccccccc}
\hline \multirow{2}{*}{$\begin{array}{c}\text { Evaluation } \\
\text { Period (Year) }\end{array}$} & \multicolumn{3}{c}{ Evaluation index } & Evaluation level & $\begin{array}{c}\text { Expanding } \\
\text { Adaptability } A_{e}\end{array}$ \\
\cline { 2 - 4 } & $S R$ & $A_{I}$ & $V$ & & 0.0002 \\
$1966-1995$ & 0.9183 & 0.9519 & 0.0081 & & Moderate adaptation & 0.0001 \\
$1971-2000$ & 0.9248 & 0.9551 & 0.0073 & Moderate adaptation & 0.0006 \\
$1976-2005$ & 0.9162 & 0.9499 & 0.0078 & Moderate adaptation & 0.0022 \\
$1981-2010$ & 0.9040 & 0.9377 & 0.0086 & Moderate adaptation & 0.0022 \\
$1986-2015$ & 0.9011 & 0.9042 & 0.0094 & Moderate adaptation & 0.0039 \\
\hline
\end{tabular}

Note: $S R$ is the ratio of the area of the local adaptive period of the evaluation period to the area of the appropriate period of the reference period, $A_{l}$ is local adaptive, $V$ is vulnerability, and $A_{e}$ is for adaptability.

\section{Acknowledgements}

This research was jointly funded by the National Natural Science Foundation of China (41630426 and 41875022) and the Gansu Provincial Meteorological Situation Research Project (GSMAMs2017-12), China.

\section{Conflicts of Interest}

The authors declare no conflicts of interest regarding the publication of this paper.

\section{References}

Alam, M. M., Siwar, C., Jaafar, A. H. et al. (2013). Agricultural Vulnerability and Adaptation to Climatic Changes in Malaysia: Review on Paddy Sector. Current World Environment, 8, 1-12. https://doi.org/10.12944/CWE.8.1.01

Burton, I., Huq, S., Lim, B. et al. (2002). From Impacts Assessment to Adaptation Priorities: The Shaping of Adaptation Policy. Climate Policy, 2, 145-159.

Deng, Z., Zhang, Q., Xu, J. et al. (2008). Research Progress of Global Climate Warming on the Growth of Crops in Gansu. Advances in Earth Science, 23, 1070-1078. 
Elith, J., Graham, C. H., Anderson, R. P. et al. (2006). Novel Methods Improve Prediction of Species' Distributions from Occurrence Data. Ecography, 29, 129-151.

Fernanda, M. S., \& Maria, L. F. (2009). Climate Change and Its Marginalizing Effect on Agriculture. Ecologicaleconomics, 68, 896-904.

Han, L., Zhang, Q., Zhao, H., Huang, T., Jia, J., \& Zhang, X. (2016). Characteristics of Agricultural Drought Disaster Loss in Gansu Province and Its Response to Climate Warming. Journal of Desert Research, 36, 767-776.

Lei, J., \& Xu, H. (2010). Prediction of Potential Distribution Area of Solidago canadensis in China Based on MaxEnt. Journal of Ecology and Rural Environment, 26, 137-141.

Ma, Y., Li, D., Yu, J. et al. (2013). The Relationship between the Distributed Genus and Climatic Factors of Chinese Genus and Woody Genus. Biodiversity, 212, 177-184. https://doi.org/10.3724/SP.J.1003.2013.08102

Ning, X. (2016). Research on Environmental Adaptability of Major Food Crops in China under Climate Change. Zhengzhou: Henan University.

Philips, S. J., Anderson, R. P., \& Schapire, R. E. (2006). Maximum Entropy Modeling of Species Geographic Distributions. Ecological Modelling, 190, 231-259. https://doi.org/10.1016/j.ecolmodel.2005.03.026

Philips, S. J., Dudik, M., \& Schapire, R. E. (2004). A Maximum Entropy Approach to Species Distribution Modeling. In Proceedings of the 21st International Conference on Machine Learning (pp. 655-662). New York, USA: Association for Computing Machinery.

Ragab, R., \& Prudhomme, C. (2002). Climate Change and Water Resources Management in Arid and Semi-Arid Regions: Prospective and Challenges for the 21st Century. Biosystems Engineering, 81, 3-34. https://doi.org/10.1006/bioe.2001.0013

Shang, S., Lian, L., Ma, T., Zhang, W., \& Han, T. (2018). Temporal and Spatial Variation Characteristics of Temperature and Precipitation in Northwest China in Recent 54 Years. Arid Zone Research, 35, 68-76.

Sun, W., \& Liu, Y. (2010). Research Progress in Risk Analysis of Biological Invasion. Chinese Agricultural Science Bulletin, 26, 233-236.

Wang, Y., Xie, B., Wan, F. et al. (2007). Application of ROC Curve Analysis in Evaluation of Invasive Species Distribution Model. Biodiversity, 15, 365-372.

Zhang, Q., Han, L., Jia, J. et al. (2016). Management of Drought Risk under Global Warming. Theoretical \& Applied Climatology, 125, 187-196.

Zhou, G., \& Wang, Y. (2003). Global Ecology. Beijing: Meteorological Press.

Zhou, G., He, Q., \& Yin, X. (2015). Adaptability and Vulnerability of Chinese Vegetation/Land Ecosystem to Climate Change. Beijing: Meteorological Press. 